\title{
Design Three Trading Strategies Based on Overconfidence, Loss Aver- sion, and Herd Behaviour
}

\section{Tzuling Liu*}

The School of Economics, Xiamen University, Xiamen 361005, China. E-mail: 15220182202565@stu.xmu.edu.cn

Abstract: There is a basic assumption in the field of economics, which is people are rational. It might be taught in the first class of the principle of economics. However, this assumption could hardly be applied to the real world since people can be affected easily sometimes, especially when they cope with their assets. Thus, with combination of psychology and academic finance, behavioural finance aims to understand the effects influencing investors' decision-making. This paper will discuss some effects which can be commonly seen in the real world, overconfidence, loss aversion, and herd behaviour included.

Keywords: Behavioural Finance; Overconfidence; Loss Aversion; Herd Behaviour

\section{Introduction}

Behavioural finance is not only a new approach different from academic finance but a broader science perspective including sociology and psychology. The specialization was proven few years ago, dealing with understanding and explaining how rational and irrational traders interact. The main thesis of this paper is going to present the effects and importance of some factors which are biases that influence human behaviour over capital market. It is vital to see the link between investors' emotions and asset valuation that motivate them to change their portfolio allocations. The biases will be investigated in the paper including overconfidence, loss aversion, and herd behaviour.

\section{Literature review}

\subsection{Overconfidence}

\subsubsection{Definition}

Overconfidence bias is people's overestimation to their abilities and talents to complete tasks. In other words, it refers to the phenomenon that people's confidence in their judgments and knowledge is higher than the accuracy of these judgments ${ }^{[1]}$.

\subsubsection{Development}

Economists have been concerned about issues of overconfidence for years at least since Adam Smith, who wrote in The Wealth of Nations: "The over-weening conceit which the greatest part of men have of their own abilities, is an ancient evil remarked by the philosophers and moralists of all ages”[2]. Even for a while, there was a consensus among researchers that overconfidence is rampant. As a bias can be commonly seen and investigated, many researchers have their own ways of definition, "Dozens of studies show that people are generally overconfident their relative skills."

This is an open-access article distributed under the terms of the Creative Commons Attribution Non-Commercial License 
"Perhaps the most robust finding in the psychology of judgement is that people are overconfident", and "The tendency to evaluate oneself more favorably than others is a staple finding in social psychology" ${ }^{[3]}$.

\subsection{Loss aversion}

\subsubsection{Definition}

Loss aversion means people tend to avoid loss rather than acquiring gains of equal magnitude. In other words, the value people avoid to loss is higher than that of acquiring the same size of gains, which implies that this bias refers to a phenomenon that people are more sensitive to losses than to gains. Besides, the explanations of the bias can be extended that a loss can be more influential to people's choices than gains of the same magnitude.

\subsubsection{Development}

Economists have common preconception that, for the most part, people dislike risks. In addition, they believe the risk-aversion intuition is a key driver to many prominent economic applications. Evenly, some researchers thought loss aversion is perhaps the most enduring and intuitive finding in behavioural decision theory ${ }^{[4]}$.

The concept of loss aversion is one of the cornerstones of prospect theory by Daniel Kahneman and Amos Tversky, playing a central role in the theory ${ }^{[5]}$. To study the effects of loss aversion in financial economics, researchers studied through papers and experiments ${ }^{[6]}$. As a result, Great numbers of evidence were accomplished. For example, Benartzi and Thaler illustrated loss aversion with offering potential explanation for the equity premium puzzle, arguing that people are reluctant to invest in stock market because of loss aversion and short planning horizons. Barberis et al. considered loss aversion in a multiperiod context, where investors update the reference point through time, arguing that sluggish updating rules might be the explanation of equity premium puzzle. Moreover, Mellers, Schwartz, Ho, and Ritov also found the different intensity to gains and losses through asking people to rate their emotional outcomes of mixed gambles. Therefore, the three researchers along with Gomes took numerical techniques to solve the problem about loss-aversion investors' portfolios separately.

\subsection{Herd Behaviour}

\subsubsection{Definition}

Herd behaviour, refers to a tendency of people to mimic actions, of a large group. In other words, herding can be defined as a phenomenon of people deciding to follow others and imitating group behaviours rather than deciding independently and automatically on the basis of their own, private information. It occurs when a group of investors change their portfolio allocations which means buy or sell the same securities based on the same, or correlated, information signals, over some period of time ${ }^{[7]}$.

\subsubsection{Development}

The bias has its roots in Keynes, who focused on the motivations to imitate and follow the crowd in a world of uncertainty. Keynes considered herding as a response to uncertainty and individual's perceptions of their own ignorance, conceiving people may follow crowds since they think the rest of the crowd are better informed. Since then, scientists have engaged in the research of herding with different approaches. For instance, Kirman use Markov chain approach to present his "ant" model, in which ants "convert" by copying another. Also, similar model can be found in Bayesian hypothesis: information composed of others' actions is used when adjusting probabilities and expectations, which generate herd behaviour and "information cascades". Topol analysed herding as the outcome of rational trades in which traders weight information about the price paid by other traders against their own judgements and of fundamental value. Acemoglu analysed rational learning about the people's decision making through signal extraction from aggregate data. Austrian economists Hayek, well known as Keynes' rivalry, also had his own insight about the knowledge as path-independent process ${ }^{[8]}$.

\section{Biases I am examining}

\subsection{Overconfidence}

\subsubsection{What is it?}


Overconfidence is a bias that people overestimate their precision of their estimates and predictions ${ }^{[9]}$. It will lead to miscalibration, better-than-average effect, illusion of control, excessive optimism, overtrading, and little diversification, causing predictable returns and higher risks.

\subsubsection{Why is it matter to the topic?}

Overconfident investors can be commonly seen in financial market, believing they can defeat over the market and earn lots of profits. However, investors are just a small part in comparison with the market. Like the rabbit in the race of the turtle and the hare, those who are overconfident rarely win.

\subsection{Loss aversion}

\subsubsection{What is it?}

Loss aversion refers to a phenomenon that people are more sensitive to losses than to gains. Besides, the explanations of the bias can be extended that a loss can be more influential to people's choices than gains of the same magnitude. This will cause disposition effect which will let investors lose relatively large amount of money.

\subsubsection{Why is it matter to the topic?}

Since empirical studies show that investors are reluctant to realize losses. It is common that people dislike risks, so they are more likely to care about their losses. This makes investors tend to keep holding on to the stocks losing money for too long, selling the stocks earning profits too fast, which is a phenomenon called disposition effect. The effect prevents investors from selling the inferior-performing stocks as early as possible, avoiding people from stopping the losses in time when they still have some profits. As a result, people will suffer from huge losses when they "wake up”, but already too late for everything.

\subsection{Herd behaviour}

\subsubsection{What is it?}

Herding can be defined as a phenomenon of people deciding to follow others and imitating group behaviours rather than deciding independently and automatically on the basis of their own, private information. However, following the crowd is not always right.

\subsubsection{Why is it matter to the topic?}

In daily life, investors follow the crowd or so-called trend to decide if they are going to buy or sell stocks to change their portfolio allocations. However, the incidents happened in the past such as bubble economy in Japan because of institutional herding. Through this case, it is obvious that path-following is not always right.

\section{Application 1}

To notice the difficulty of defeating market, then trade more carefully.

Simple diversification which is $1 / \mathrm{n}$ rules can reduce systemic risks

Example 1 - Overtrading

The excessive trading of individual investors can be called the active investing puzzle. Barber and Odean (2000) investigated the performance of trading history by examining over 60,000 discount brokerage investors in United States from 1991 to 1996. Their aim is to see whether the trades of these investors were justified in the sense that they led to the improvements in portfolio performances.

The $20 \%$ of investors who traded most underperformed the market by about $10 \%$ per year as the grey bars shows. In other words, the high-turnover investors pay large fees, given their high volume of trade, which draws down their net returns ${ }^{[10,11]}$. 


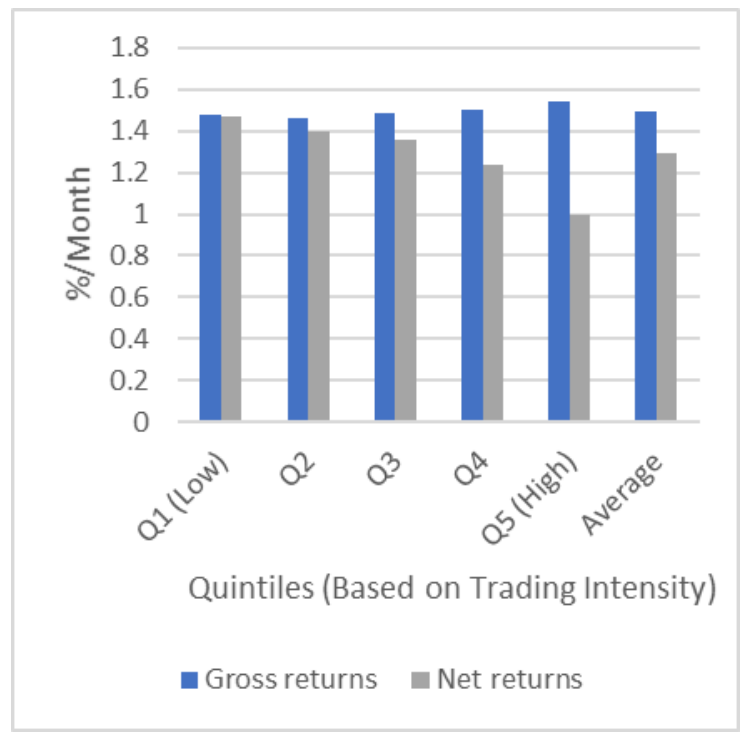

Figure 1. Gross and net returns for groups with different trading intensities

Apart from this, Barber and Odean also investigated on the connection with gender and overconfidence. They collected data consisting of over 35,000 households from a large discount brokerage firm, finding that the average turnover rate of common stocks for men is higher than for women by $45 \%$. However, men earned $1.4 \%$ less on a risk-adjusted basis. The consequence would be even more dramatic in terms of single men and single women: the average turnover rate of common stocks for single men is over one and a half time than that for single women, but after risk adjustment, single men earned $2.3 \%$ less than single women ${ }^{[12]}$.

Solution: It is hard to come up with concrete advice to solve the problem caused by overconfidence, but realize the fact that it's difficult to defeat over market and trade more carefully may do investors good.

Example 2 - Little diversification

Insufficient diversification now has become a well-studied object. Jacob et al indicate that if choosing wisely, an investor only needs to hold a few stocks then he (or she) can reduce systemic risk significantly. NAIC also suggests the number of stocks investors hold on in the portfolio should be no less than five. Nonetheless, an early research held by Blume, Crockett, and Friend showed that $34.1 \%$ of investors hold only one stock that pays dividends, $50 \%$ of investors hold stocks no more than two, and only $10.7 \%$ of investors hold stocks more than ten. Furthermore, in Blume and Friend's research, $70 \%$ of investors' extent of actual diversification is lower than the recommendation quantity of stocks in the portfolio ${ }^{[13]}$.

Solution: Simple diversification which is $1 / \mathrm{n}$ rules from Benartzi and Thaler can be taken. Due to the different structure of random selection, the direct method is quite useful. Individuals can end up with risks that are too small or excessive relative to their risk tolerance.

\section{Application 2}

Sell the inferior-performing stocks as soon as possible and keep the superior-performing stocks longer.

Researchers has noticed that investors will sell the superior-performing stocks too early whereas keeping holding on to stocks that losing money for too long. This kind of tendency was called disposition effect.

The disposition effect was first proposed by Shefrin and Statman who combined prospect theory from Kahneman and Tversky with emotions of pride and regret. Past empirical evidence about disposition effect have been found by many researchers including Lakonishok and Smidt, Ferris, Haugen, and Makhija, Odean, and Health, Huddart, and Lang .

Example - disposition effect

Odean has done research using the data including trading records for 10,000 discount brokerage accounts with almost 100,000 transactions between 1987 and 1993, carefully documented the tendency of individuals investors to sell 
winners and keep holding on to losers. Through focusing on the ratio of winner/loser sales relative to the opportunities for winner/loser sales ${ }^{[14]}$. Specifically, he calculated the proportion of gains realized (PGR) as:

PGR= Realized Gains/ (Realized Gains+ Paper Gains)

Similarly, the proportion of losses realized (PLR) as:

PLR $=$ Realized Losses/ (Realized Losses+ Paper Losses)

Table 1 Aggregate Proportion of Gains (PGR) and Losses Realized (PLR) (\%)

\begin{tabular}{|l|l|l|l|}
\hline & Entire year & December & January-November \\
\hline PLR & 0.098 & 0.128 & 0.094 \\
\hline PGR & 0.148 & 0.108 & 0.152 \\
\hline Difference in proportions & -0.050 & 0.020 & -0.058 \\
\hline t-statistics & -35 & 4.3 & -38 \\
\hline
\end{tabular}

Solution: Instead of waiting for the reversal of stocks that lose money, sell the losers as soon as possible. Also, about the superior-performing stocks, don’t rush to sell them, combine all relevant information you have before making decision.

\section{Application 3}

Instead of following crowds, select stocks which is not so popular (anti-herding)

Herd behaviour itself has something to do with social component. Analysts may herd if influenced by recommendations or earnings estimates by other analysts, then it is likely that herd behaviour exists in the source of certain anomalies. Furthermore, research indicates that analysts go with the crowd when it comes to recommendation revision

Example - Using U.K. data

Wyile tested for herding among U.K. equity mutual fund managers, employing a new data set of the portfolio holdings of 268 U.K. equity funds in the period from January 1986 to December 1993. With LSV measure, the researcher found that the level of herding strongly increased in the number of the managers trading a stock in a particular period. Furthermore, with the test following the methodology developed in Wermers, the excess returns are small or negative when funds herd most strongly into large stocks and positive in the periods that they herd most strongly out of stocks.

The buy herding observations are sorted into quintiles by the level of adjusted LSV herding, with quintile 1 having the highest level of herding. Likewise for sell-herding quintiles, except that quintile 5 has the highest level of herding. The excess returns, using the stock characteristic-based benchmark developed by Daniel, Grinblatt, Titman, and Wermers, are then calculated for the herding period and cumulative periods before and after the herding period ${ }^{[15]}$.

Table 2 Cumulative Excess Returns (\%) of Herding Deciles before and after Herding Period for the 200 Largest Stocks on the London Stock Exchange

\begin{tabular}{|c|c|c|c|c|c|c|c|}
\hline \multicolumn{8}{|l|}{ Herding Period } \\
\hline Quintile & -12 & -3 & -1 & 0 & 1 & 3 & 12 \\
\hline \multicolumn{8}{|c|}{ Buy Herding Stock Periods (bit/nit $\geqq \rho t$ ) } \\
\hline B1 (Heavy buying) & $\begin{array}{l}0.021 \\
(0.47)\end{array}$ & $\begin{array}{l}0.02 \\
(0.17)\end{array}$ & $\begin{array}{l}-0.07 \\
(-2.41)\end{array}$ & $\begin{array}{l}-1.19 \\
(-5.36)\end{array}$ & $\begin{array}{l}0.05 \\
(1.58)\end{array}$ & $\begin{array}{l}-0.08 \\
(-0.97)\end{array}$ & $\begin{array}{l}-0.71 \\
(-1.91)\end{array}$ \\
\hline $\mathrm{B} 2$ & $\begin{array}{l}0.46 \\
(0.98)\end{array}$ & $\begin{array}{l}-0.42 \\
(-4.77)\end{array}$ & $\begin{array}{l}-0.18 \\
(-4.83)\end{array}$ & $\begin{array}{l}0.65 \\
(-4.18)\end{array}$ & $\begin{array}{l}-0.09 \\
(-3.38)\end{array}$ & $\begin{array}{l}-0.39 \\
(-5.40)\end{array}$ & $\begin{array}{l}-1.48 \\
(-3.97)\end{array}$ \\
\hline B3 & $\begin{array}{l}-1.29 \\
(-3.58) \\
\end{array}$ & $\begin{array}{l}-0.46 \\
(-7.43)\end{array}$ & $\begin{array}{l}-0.25 \\
(-12.12)\end{array}$ & $\begin{array}{l}-0.55 \\
(-4.08)\end{array}$ & $\begin{array}{l}0.13 \\
(5.76) \\
\end{array}$ & $\begin{array}{l}-0.10 \\
(-1.12)\end{array}$ & $\begin{array}{l}-0.58 \\
(-1.53)\end{array}$ \\
\hline B4 & $\begin{array}{l}1.26 \\
(3.84) \\
\end{array}$ & $\begin{array}{l}0.39 \\
(3.43) \\
\end{array}$ & $\begin{array}{l}0.10 \\
(4.53) \\
\end{array}$ & $\begin{array}{l}-0.38 \\
(-2.80) \\
\end{array}$ & $\begin{array}{l}-0.03 \\
(-0.91) \\
\end{array}$ & $\begin{array}{l}0.13 \\
(1.67) \\
\end{array}$ & $\begin{array}{l}-0.39 \\
(-0.73) \\
\end{array}$ \\
\hline B5 (Light buying) & 1.88 & 0.52 & 0.15 & 0.00 & -0.08 & -0.19 & 0.36 \\
\hline
\end{tabular}




\begin{tabular}{|l|l|l|l|l|l|l|l|l|}
\hline \multicolumn{2}{|l|}{$(3.35)$} & $(4.87)$ & $(4.57)$ & $(0.01)$ & $(-1.91)$ & $(-1.38)$ & $(0.69)$ \\
\hline \multicolumn{2}{|l|}{ Sell Herding Stock Periods (bit/nit $<\rho)$} \\
\hline S1 (Light selling) & $\begin{array}{l}\text { 4.05 } \\
\text { (4.50) }\end{array}$ & $\begin{array}{l}0.99 \\
(8.32)\end{array}$ & $\begin{array}{l}0.07 \\
(2.15)\end{array}$ & $\begin{array}{l}-0.80 \\
(-3.24)\end{array}$ & $\begin{array}{l}-0.15 \\
(2.98)\end{array}$ & $\begin{array}{l}0.57 \\
(4.53)\end{array}$ & $\begin{array}{l}1.27 \\
(2.64)\end{array}$ \\
\hline S2 & 2.36 & 0.94 & 0.37 & 0.09 & -0.06 & -0.43 & -0.53 \\
& $(6.07)$ & $(11.36)$ & $(11.51)$ & $(0.47)$ & $(-2.03)$ & $(-6.23)$ & $(-1.06)$ \\
\hline S3 & 2.58 & 0.76 & 0.39 & 0.45 & 0.02 & -0.08 & 0.14 \\
& $(7.34)$ & $(14.19)$ & $(19.15)$ & $(2.55)$ & $(0.70)$ & $(-0.97)$ & $(0.33)$ \\
\hline S4 & 2.44 & 0.49 & 0.37 & 1.58 & -0.14 & -0.15 & 0.31 \\
& $(5.41)$ & $(5.57)$ & $(10.86)$ & $(7.67)$ & $(-3.21)$ & $(-1.39)$ & $(0.49)$ \\
\hline S5 (Heavy selling) & 6.52 & 1.38 & 0.72 & 0.95 & -0.21 & -0.05 & 0.34 \\
& $(6.62)$ & $(15.83)$ & $(20.08)$ & $(3.24)$ & $(-4.42)$ & $(-0.38)$ & $(0.49)$ \\
\hline B1 minus S5 & -6.29 & -1.35 & -0.79 & -2.14 & -0.26 & -0.02 & -1.05 \\
& $(-8.89)$ & $(-17.3)$ & $(-19.5)$ & $(-14.2)$ & $(-5.55)$ & $(-0.99)$ & $(-2.03)$ \\
\hline
\end{tabular}

Solution: Instead of following the trend, anyone in any organization should keep the separate identity. It is crucial to make judgements yourself to prevent from being driven by the social forces. Also, try buy stocks of some small companies full of potential, maybe you will be the next Buffett one day.

\section{Conclusion}

The three biases explained in this paper show how psychological factors have impacts on investors' decision making. Overconfidence causes insufficient diversification in the portfolio and excessive trading, resulting in lower returns and higher risks. Loss aversion can lead to disposition effect, which is a phenomenon that investors tend to sell the superior-performing stocks prematurely, while holding on to inferior-performing stocks for too long to wait for the reversal. Herd behaviour which means path-following also has its weakness, since evidence shows that herding results in predictable returns.

\section{References}

1. $\quad$ Heller Y. Overconfidence and diversification. American Economic Journal: Microeconomics 2014; 6(1): 134-153. doi: $10.2307 / 43189656$.

2. Malmendier U, Taylo T. On the verges of overconfidence. The Journal of Economic Perspectives 2015; $29(4)$ : 3-7.

3. Benoît JP, Dubra J. Apparent overconfidence.econometrica 2011; 79(5): 1591-1625.

4. Berejikian JD, Early B. Loss aversion and foreign policy resolve. Political Psychology 2013; 34(5): 649-671.

5. Berkelaar A, Kouwenberg R, Post T. Optimal portfolio choice under loss aversion. The Review of Economics and Statistics 2004; 86(4): 973-987.

6. Bodnaruk A, Simonov A. Loss-averse preferences, performance, and career success of institutional investors. The Review of Financial Studies 2016; 29(11): 3140-3176.

7. Kim KA, Nofsinger JR. Institutional herding, business groups, and economic regimes: evidence from Japan. The Journal of Business 2005; 78(1): 213-242.

8. Baddele M. Herding, social influence and economic decision-making: socio-psychological and neuroscientific analyses. Philosophical transactionsof the royal society of London 2010; 365(1538): 281-290.

9. Van den Steen E. Overconfidence by Bayesian-Rational agents. Management Science 2011; 57(5): $884-896$.

10. Barber B, Odean T.. Trading is hazardous to your wealth: The common stock investment performance of individual investors. The Journal of Finance 2000; 55(2): 773-806.

11. Daniel K, Hirshleifer D. Overconfident Investors, Predictable Returns, and Excessive Trading. The Journal of Economic Perspectives 2015; 29(4): 61-87.

12. Barber B, Odean T. Boys will be boys: Gender, overconfidence, and common stock investment. The Quarterly Journal of Economics 2001; 116(1): 261-292.

13. Shefrin, H Beyond Greed and Fear: Understanding behavioral Finance and the psychology of investing; 2002. doi: 10.1093/0195161211.001.0001.

14. Ackert L, Deaves R. Behavioral Finance: Psychology, Decision-Making, and Markets. ; 2010.

15. Wylie S. Fund Manager Herding: A Test of the Accuracy of Empirical Results Using U.K. Data. The Journal of Business 2005; 78(1): 381-403. doi:10.1086/426529. 